\title{
Linkage studies in dominant optic atrophy, Kjer type: possible evidence for heterogeneity
}

Mary J Seller, Joseph T Behnam, Cathryn M Lewis, Robert L Johnston, Michael A Burdon, David J Spalton

\begin{abstract}
Dominant optic atrophy, Kjer type, is an autosomal dominant disorder causing progressive loss of visual acuity and colour vision from early childhood. The gene (OPA1) has variable expressivity, a penetrance of 0.98 , and the locus has been localised to 3q28-29. We have genotyped nine British families with the disease using 12 polymorphic microsatellite markers from this region. Linkage and haplotype analysis shows the OPA1 gene to be located in a $2.3 \mathrm{cM}$ interval between markers D3S1601 and D3S2748. One family showed no evidence of linkage with the chromosome 3 markers, suggesting for the first time that locus heterogeneity for this disease may exist, although exclusion for linkage is based on unaffected subjects. In addition, analysis of recombinants has enabled us to order the 12 markers along chromosome 3.

(F Med Genet 1997;34:967-972)
\end{abstract}

Keywords: dominant optic atrophy (Kjer type); linkage analysis; genetic heterogeneity

Kjer type juvenile optic atrophy (MIM $165500)^{1}$ is an autosomal dominant disorder, believed to have a frequency of around 1 in $50000 .^{2}$ Described first by Kjer, ${ }^{3}$ it arises in childhood before the age of about 8 years with insidious onset of symptoms and has a slowly progressive course. There is a variable reduction in visual acuity, loss of colour perception, characteristically in the blue-yellow axis, and temporal or diffuse disc pallor. ${ }^{4-6}$ Pathological studies suggest that the retinal ganglion cells are affected. ${ }^{78}$

The gene (OPA1) appears to have variable expression, for the phenotype ranges from mild visual impairment to severe: some people continue to lead a normal life while others are registered as blind. In 1994, the gene was mapped to the telomeric region of $3 \mathrm{q}$ by Eiberg $e t a l^{P}$ in three large Danish pedigrees. Refinement of the position to $3 \mathrm{q} 28-29$ was achieved in a large Cuban family ${ }^{10}$ and subsequently in four French families ${ }^{11}$ and in a single multigenerational American family. ${ }^{12}$ We previously confirmed the localisation of the OPAl gene to the same region of chromosome 3 in a large multigeneration extended British pedigree ${ }^{13}$ using seven microsatellite markers. Votruba et al ${ }^{14}$ have recently published similar data on their British families. The original Danish group has now refined the OPA1 locus to a $1.4 \mathrm{cM}$ interval. ${ }^{15}$ All the studies so far have suggested that the penetrance is almost full $(0.98)$ and there is no genetic heterogeneity in this disorder. We now present our findings using 12 polymorphic microsatellite markers from 3q28-q29 in nine British families, in which we suggest for the first time that locus heterogeneity may exist for this disorder.

\section{Materials and methods}

Blood or mouthwash samples were obtained from 108 members of nine British families (pedigrees shown in fig 1 ) residing in London and the Home Counties, the Midlands, and south west England. They were visited at home by either of two ophthalmologists with neurophthalmic expertise. Subjects were classified as definitely affected, possibly affected, or not affected using a protocol which had been validated in our earlier study. ${ }^{13}$ It was based on the following features: insidious onset under 10 years of age; apparent autosomal dominant inheritance; reduced Snellen visual acuity; temporal or diffuse pallor of the optic disc; reduced colour vision using Ishihara and HRR plates; and centrocecal desaturation of a red target on confrontation field testing. Particular weight was given to the presence of temporal or diffuse optic disc pallor even in the absence of visual acuity or significant colour vision defects when the person was part of a pedigree with known autosomal dominant optic atrophy. Children were examined but not all were able to provide samples. The assignment of clinical status was made before the DNA studies.

Genomic DNA was prepared using a "Puregene" DNA isolation kit (Gentra Systems Inc). Twelve polymorphic microsatellite markers located in 3q27-3q29 were used for genotyping: D3S1314, D3S2747, D3S1601, D3S2418, D3S3669, D3S2305, D3S3562, D3S3590, D3S2748, D3S1305, D3S3642, and D3S1265. The oligonucleotide sequences of the primer pair of each were obtained from Généthon (http://www.genethon.fr) or the Genome Database (http://gdbwww.gdb.org), and HPLC purified primers with the $5^{\prime}$ end fluorescently labelled were made (Oswel DNA Services, Southampton, UK). PCR of the genomic DNA (100 ng) was performed with 10 pmol of each primer, $5 \mu \mathrm{mol} / 1$ of each deoxynucleotide triphosphate, 0.5 U Taq polymerase, $1.5 \mathrm{mmol} / 1$ magnesium chloride, and standard Taq polymerase buffer (Promega Corporation, Southampton, UK) using 35 amplification cycles of $94^{\circ} \mathrm{C}$ for 40 seconds and $55^{\circ} \mathrm{C}$ for one minute, and a final extension 

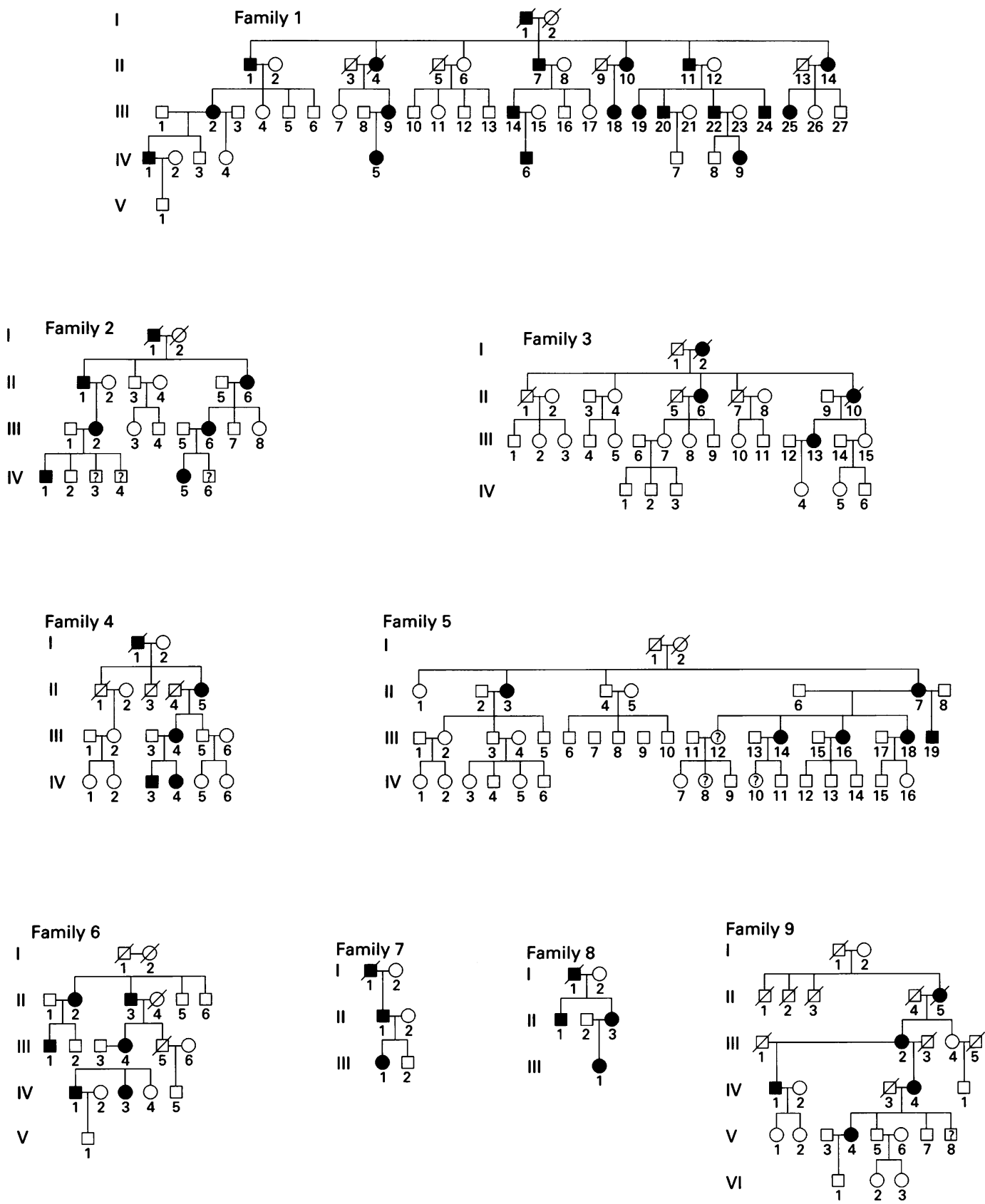

Figure 1 Partial pedigrees of the nine families with dominant optic atrophy. Black circles (females) and squares (males) represent affected subjects; unrelated spouses and unaffected family members are represented as white circles or squares; possibly affected subjects on clinical examination have a question mark.

phase of 10 minutes at $72^{\circ} \mathrm{C}$. Subjects were typed for each marker in a single PCR reaction first, and then the results were confirmed at least three times by multiplex PCR with up to

Table 1 Pairwise lod scores obtained in all nine OPA families with D3S2305. Note negative scores for family 2

\begin{tabular}{lrrrrrr}
\hline \multirow{7}{*}{ Family } & \multicolumn{7}{c}{ Recombination fraction $(\theta)$} \\
\cline { 2 - 7 } & \multicolumn{1}{c}{0.00} & 0.01 & \multicolumn{1}{l}{0.05} & \multicolumn{1}{l}{0.1} & \multicolumn{1}{l}{0.2} & \multicolumn{1}{c}{0.3} \\
\hline 1 & 2.84 & 2.81 & 2.68 & 2.47 & 1.94 & 1.33 \\
2 & -8.30 & -3.16 & -1.70 & -1.01 & -0.39 & -1.13 \\
3 & 1.09 & 1.07 & 0.97 & 0.84 & 0.57 & 0.31 \\
4 & 0.90 & 0.88 & 0.81 & 0.72 & 0.54 & 0.36 \\
5 & 1.81 & 1.77 & 1.63 & 1.44 & 1.04 & 0.60 \\
6 & 2.08 & 2.04 & 1.88 & 1.67 & 1.23 & 0.75 \\
7 & 0.29 & 0.28 & 0.25 & 0.21 & 0.13 & 0.62 \\
8 & 0.30 & 0.30 & 0.28 & 0.26 & 0.20 & 0.15 \\
9 & 1.28 & 1.26 & 1.17 & 1.06 & 0.84 & 0.59 \\
Total & 1.82 & 6.79 & 7.54 & 7.28 & 5.80 & 3.82 \\
\hline
\end{tabular}

six markers per reaction, for which the magnesium chloride was changed to $2 \mathrm{mmol} / \mathrm{l}$.

Electrophoresis of the PCR amplified microsatellite alleles was undertaken on a $36 \mathrm{~cm}$ long $6 \%$ denaturing polyacrylamide sequencing gel (Sequagel 6, National Diagnostics) in $1 \times$ TBE buffer for 14 hours at $1200 \mathrm{~V}, 650$ PMT in an ABI 373 automated fluorescence DNA sequencer, including a fluorescence labelled internal standard, $0.5 \mu \mathrm{l} /$ lane (Genescan-350, Perkin Elmer). Sizing of the alleles to single base resolution was done using GENESCAN software/ABI Model 672, and the DNA fragment analysis software package "Genotyper" (Applied Biosystems) was used for allele assignment.

Two point linkage analysis was performed for each marker against the disease locus and lod scores calculated using the MLINK 


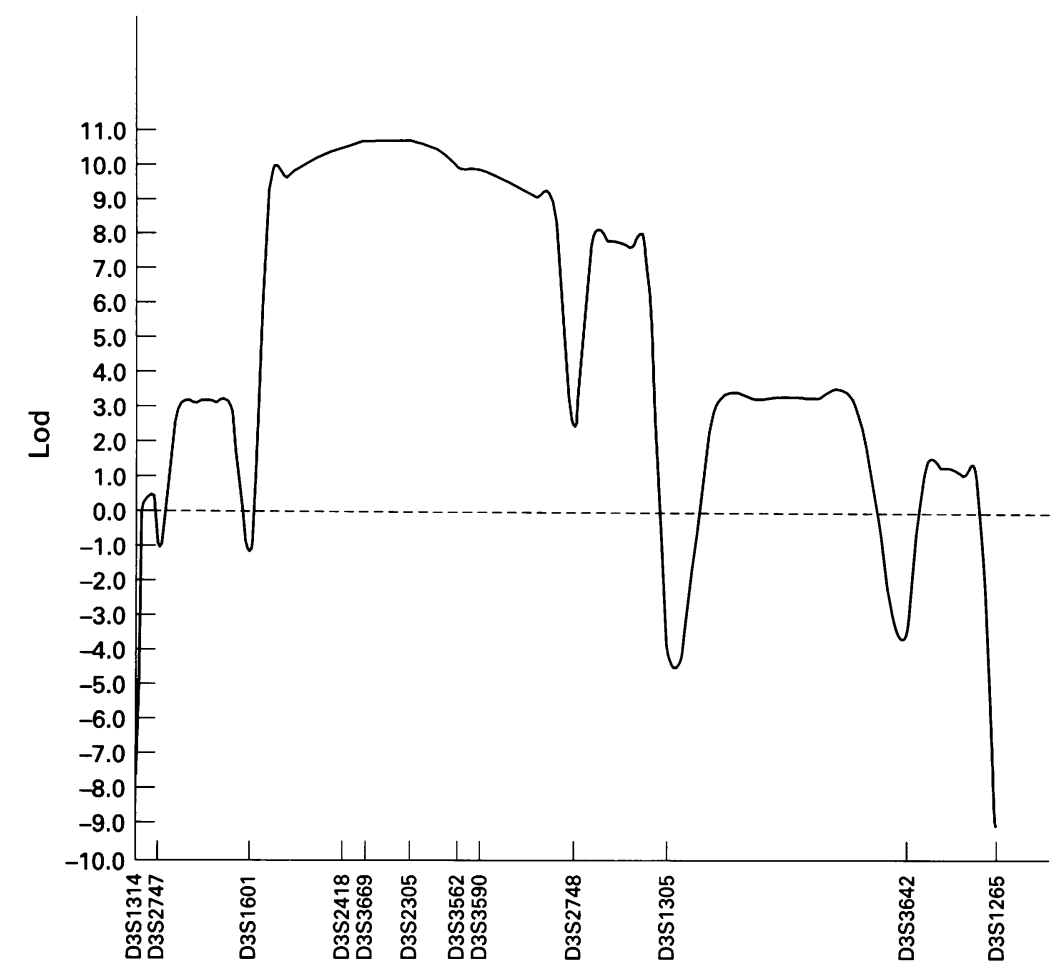

Figure 2 Multipoint lod scores between the OPA1 gene and 12 markers on chromosome $3 q$.

program from FASTLINK ${ }^{16-18}$ using a gene frequency for OPA1 of 0.00001 and a penetrance of 0.98 . The allele frequencies for each marker were estimated from married in spouses from all pedigrees ( 36 chromosomes). Subjects designated "possibly affected" on clinical grounds were entered as of unknown phenotype for the linkage analysis. Multipoint analysis using the 12 markers was done with
GENEHUNTER $^{19}$ and homogeneity analysis was performed using the HOMOG program of the LINKAGE package. ${ }^{20}$

The marker order suggested by pedigree data from this study was determined using CRI$\mathrm{MAP}^{21}$ and compared to that given by the latest Généthon $\operatorname{map}^{22}$ and the database of Cedar Genetics (http://cedar.genetics.soton.ac.uk) and the Whitehead Institute for Biomedical Research/MIT Center for Genome Research (http://www.genome.wi.mit.edu).

\section{Results and discussion}

The 108 subjects who were genotyped were classified clinically as follows: 49 were affected, seven possibly affected, and 34 unaffected together with 18 unaffected spouses. When two point linkage analysis was performed for each marker in each family, although positive total lod scores were obtained with all markers, family 2 consistently had negative values, suggesting that it was different from the other eight families. This is shown for marker D3S2305 in table 1 . A homogeneity analysis was performed on family 2 , and this suggested that family 2 was unlinked to this region, probability of linkage 0.00 ; evidence for genetic heterogeneity was statistically significant $(p=0.015)$. Thus, this family was omitted from the remainder of the linkage analysis. Multipoint analysis with markers D3S3669 and D3S2305 in all families gave a maximum lod score of 12.6 , but without family 2 it increased to 14.0 .

In performing multipoint analysis across all 12 markers, the GENEHUNTER program pruned family 1 , taking out the less informative subjects and resulting in slightly lower lod

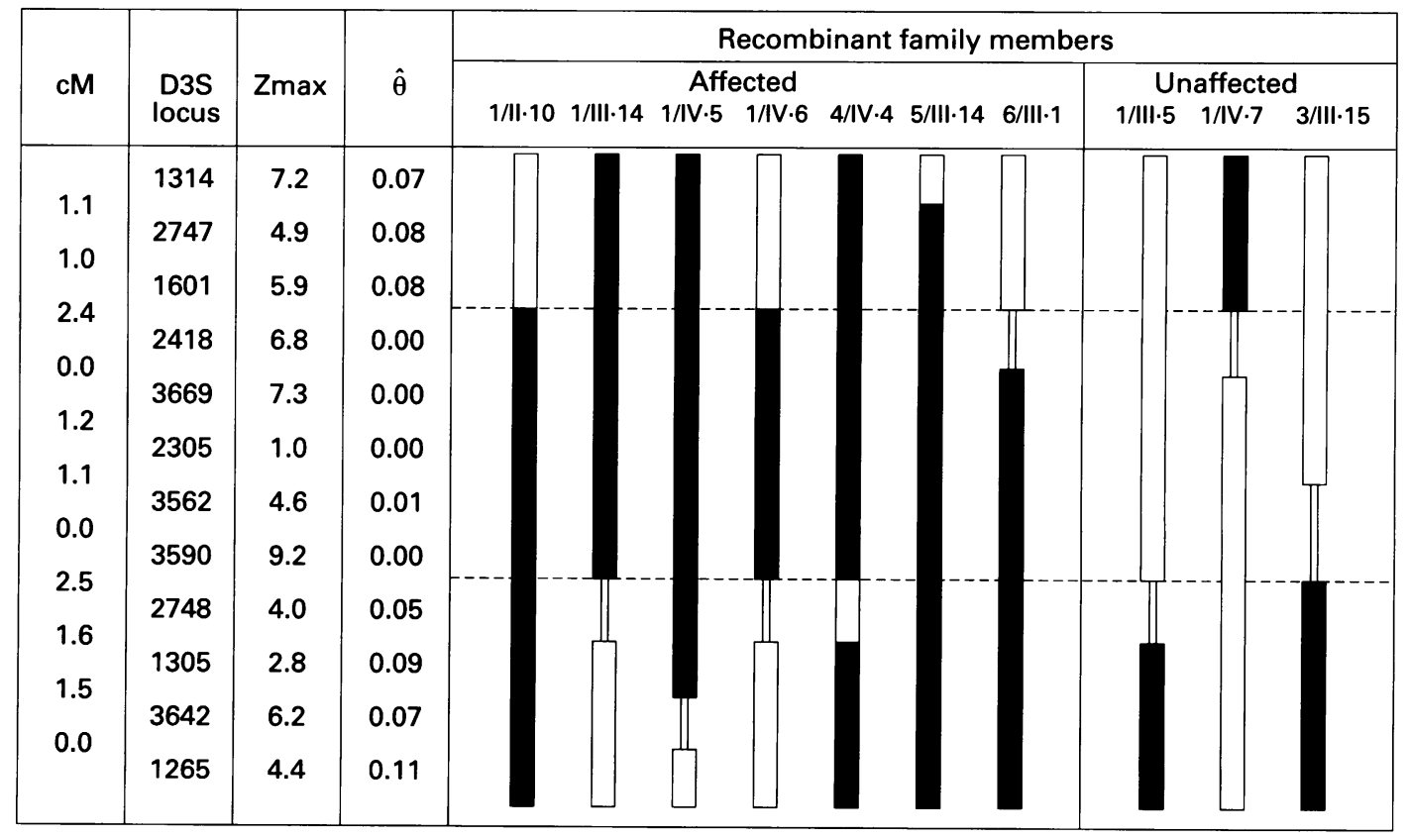

Figure 3 Schematic representation of two point linkage and recombinant analysis between OPA1 and chromosome $3 q$ markers. Twelve genetic markers mapping to chromosome 3q27-qter are listed on the left from centromeric (top) to telomeric (bottom). The intermediate distances (cM) on the extreme left and the order are the CRI-MAP estimations based on marker genotypes from all families. The maximum lod score (Zmax) obtained with each marker is shown together with the recombinant frequency $(\hat{\theta})$ at which the Zmax occurred. Recombinant subjects are listed by status, family, generation, and pedigree number at the top of the figure which corresponds to fig 1. The bars below each subject show the haplotype data for each person: black=haplotype apparently associated with the disease; white=haplotype apparently not associated with the disease; thin double line=phase unknown or uninformative genotype; the area between the dashed lines is the disease interval. 1/IV.6 is a recombinant distally and the son of 1/III.14 who is himself a recombinant proximally. 4/IV.4 appears to interval. $1 /$ IV 6 is a recombin 
Family 2

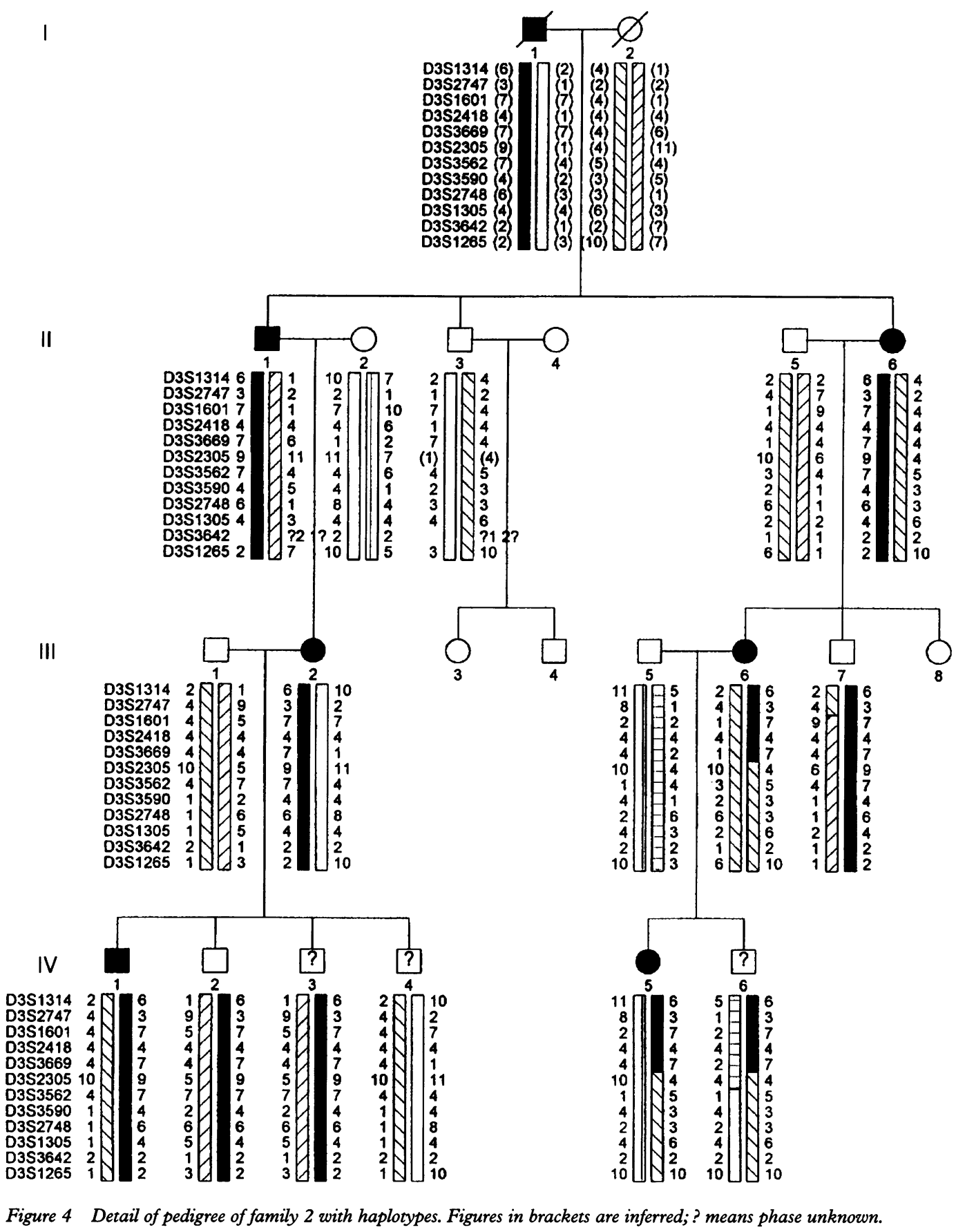

scores. The maximum lod score was relatively flat between markers D3S1601 and D3S2748 (fig 2), but was maximised at 10.7 between markers D3S2418 and D3S3562.

Haplotypes were constructed for all family members and in all pedigrees except two there was a distinctive haplotype segregating with the disease. No common marker haplotype was seen in the families, suggesting that no founder effect was detected at this level of marker density. There were 10 recombinant meioses involving the disease haplotype (fig 3) in 12 subjects, of which eight were particularly informative. Three affected subjects (1/II.10, 1/IV.6, 6/III.1) and one unaffected aged 24 years (1/IV.7) were recombinants at locus D3S1601. Two affected (1/III.14, 1/IV.6) and one unaffected (aged 52 years) (1/III.5) subjects were recombinants for the marker D3S1305. Unfortunately, the next most proximal locus, D3S2748, was uninformative in those three subjects. However, an affected female in family 4 (IV.4) was a double recombinant either side of this locus (consistent results, repeated six times on two different DNA samples), and an unaffected subject in family 3 (III.15) aged 32 years was also a recombinant at this locus. Recombinant analysis therefore allows us to place the disease gene between locus D3S1601 proximally and the 
Table 2 Clinical findings and clinical classification of family 2 members

\begin{tabular}{|c|c|c|c|c|c|c|}
\hline \multirow[b]{2}{*}{ Subject } & \multirow[b]{2}{*}{ Age } & \multirow{2}{*}{$\begin{array}{l}\text { Visual acuity } \\
\text { (better eye) }\end{array}$} & \multicolumn{2}{|c|}{ Colour vision (better eye) } & \multirow[b]{2}{*}{ Disc appearance } & \multirow[b]{2}{*}{ DOA clinical statust } \\
\hline & & & Ishihara & $H R R^{\star}$ & & \\
\hline II. 1 & 68 & $3 / 60$ & $1 / 17$ & No plates seen & Diffuse pallor & Definitely affected \\
\hline II. 3 & 61 & $6 / 6$ & $16 / 17$ & Normal & Normal & Unaffected \\
\hline II. 6 & 56 & $6 / 60$ & $0 / 17$ & No plates seen & Diffuse pallor & Definitely affected \\
\hline III. 2 & 40 & $6 / 9$ & $12 / 17$ & Mild red-green & Temporal pallor & Definitely affected \\
\hline III. 6 & 33 & $6 / 24$ & $1 / 17$ & No plates seen & Diffuse pallor & Definitely affected \\
\hline III. 7 & 25 & $6 / 4$ & $17 / 17$ & Normal & Normal & Unaffected \\
\hline IV.1 & 17 & $6 / 6$ & $4 / 17$ & Mild red-green & Temporal pallor & Definitely affected \\
\hline IV. 2 & 16 & $6 / 5$ & $17 / 17$ & Normal & Normal & Unaffected \\
\hline IV.3 & 13 & $6 / 4$ & $13 / 17$ & $\begin{array}{l}\text { Unclassifiable defect on } \\
\text { screening series }\end{array}$ & $\begin{array}{l}\text { Minimal temporal } \\
\text { pallor }\end{array}$ & Possibly affected \\
\hline IV.4 & 10 & $6 / 4$ & $10 / 17$ & $\begin{array}{l}\text { Unclassifiable defect on } \\
\text { screening series }\end{array}$ & $\begin{array}{l}\text { Minimal temporal } \\
\text { pallor }\end{array}$ & Possibly affected \\
\hline IV.5 & 6 & $6 / 9$ & $0 / 17$ & Mild red-green & Diffuse pallor & Definitely affected \\
\hline IV.6 & 3 & $6 / 9$ & Unable & form & $\begin{array}{l}\text { Minimal temporal } \\
\text { pallor }\end{array}$ & Possibly affected \\
\hline
\end{tabular}

${ }^{\star}$ HRR=Hardy Rand Rittler pseudoisochromatic plates.

†DOA=dominant optic atrophy.

locus D3S2748 distally, an interval of $2.3 \mathrm{cM}$ based on the most recent Généthon map. ${ }^{22}$ In addition, there is no evidence in our families of recombination of the OPA1 gene locus with the loci D3S2418, D3S3669, D3S2305, or D3S3590. Jonasdottir et $a l^{15}$ have refined the interval to $1.4 \mathrm{cM}$ between D3S3669 and D3S3562, but the order of their markers differs from ours and from the Généthon map, ${ }^{22}$ while Votruba et $a l^{14}$ found the flanking markers D3S3590 and D3S1305 and Brown et al ${ }^{12}$ D3S3669 and D3S1305, intervals of 2.4 and $3.8 \mathrm{cM}$ respectively on the Généthon map.

The order of the 12 chromosome 3 markers and the intermarker distances were estimated based on marker genotypes from all families and are shown on the left side of fig 3 . The best order is cen-D3S1314-D3S2747-D3S1601D3S2418 - D3S3669 - D3S2305 - D3S3562 D3S3590 - D3S2748 - D3S1305 - D3S3642 D3S1265-tel. This broadly corresponds to the 1996 Généthon map $^{22}$ and that of Cedar Genetics; however, recombinant events have allowed us to order several markers not specified on this map and to integrate the two markers we have used derived from Cedar Genetics. A crossover in subject 5/III.14 (fig 3) places D3S2747 telomeric to D3S1314, and recombinants from two separate meioses (in 1/II.10 and 1/IV.6, fig 3) place D3S2418 telomeric to D3S1601. A crossover in 2/III.6 (fig 4) orders D3S2305 telomeric to D3S3669, and one in 2/IV.6 (fig 4) orders D3S2305 centromeric to D3S3562. D3S3590 is ordered centromeric to D3S2748 by a recombinant in 4/IV.4 (fig 3) and D3S1305 centromeric to D3S3642 by a crossover in subject 5/III.12 (data not shown).

Our order is the same as that arrived at by Brown et $a l^{12}$ in American families, but differs from that found in Danish families, ${ }^{15}$ our order compared with that of the Danish workers fitting our data significantly better with odds greater than $1: 100$.

In the eight families where the disease mapped to chromosome 3, there were four subjects who were considered to be possibly affected: three members of family 5 (III.12, IV.8, and IV.10) and V.8 in family 9. All except $5 /$ IV.10 were found to bear the complete haplotype segregating with the disease in their family; 5/IV.10 was a recombinant, but only at the most proximal locus D3S1314 (fig 3), so bore the remainder of the haplotype. Clinically, family 5 was mildly affected; even those members of more advanced years did not have severe visual impairment.

Family 2 on linkage analysis gave negative lod scores. The pedigree with haplotypes is shown in fig 4 and the clinical examination findings and clinical classification are shown in table 2 . On clinical examination, affected subjects II.1, II.6, and III.6 had the classical stigmata of dominant optic atrophy. Subjects III. 2 and IV.1, though clearly affected, with disc pallor and significantly defective colour vision, had visual acuity within the normal range. Subjects IV.3 and IV.4 (aged 13 and 10 years) were clinically very similar, having excellent visual acuity but mildly defective colour vision and minimal temporal pallor of the optic discs. They were both classified clinically as possibly affected. Subjects II.3, III.7, and IV. 2 had an entirely normal examination and were regarded as unaffected. The absence of any other neurological, developmental, or congenital abnormalities is thought by many to be part of the clinical picture of dominant optic atrophy, although $\mathrm{Hoyt}^{4}$ has described sensorineural hearing loss as an association, and $\mathrm{Kjer}^{3}$ noted mental retardation in $10 \%$ of his cases. No subject in family 2 had subjective hearing difficulties and there were no subjects with mental retardation, although a detailed neurological examination was not performed. The clinical picture in affected members of family 2 was similar to that of affected members of the other families in the study.

On haplotype analysis, a haplotype segregated with the disease in subjects II.1, II.6, and III.2, but was also found in III.7 and IV.2 (aged 25 years and 16 years respectively), who were clinically clearly unaffected, and in one of the latter's possibly affected brothers (IV.3) but not the other (IV.4) (table 2). A recombinant at locus D3S2305 was present in affected III.6 and her two offspring, IV.5 and IV.6, the former aged 6 being affected, while the latter was only 3 years and although the clinical examination was incomplete, he was considered possibly affected. The genotyping in these subjects was 
repeated on two separate DNA samples from each person and no inconsistencies were found.

While in this family there is no affected subject without at least part of the haplotype associated with the disease, there is statistically significant evidence on homogeneity analysis for a lack of linkage of the disease to chromosome 3. Thus the evidence against linkage comes essentially from unaffected subjects and this is always less satisfactory than from affected subjects because of the issue of non-penetrance. However, in none of the other eight families studied was a non-penetrant carrier found, so this clustering of two such cases in one pedigree is striking. It is therefore possible that this family has another form of dominant optic atrophy, the locus of which is elsewhere in the genome. This is the first suggestion that locus heterogeneity might exist for dominant optic atrophy, Kjer type.

We gratefully acknowledge the generous financial support of the Iris Fund for Research into Blindness.

1 McKusick VA. Mendelian inheritance in man. 10th ed. Baltimore: Johns Hopkins University Press, 1992.

2 Lyle WM. Genetic risks. Waterloo, Ontario: University of Waterloo Press, 1990.

3 Kjer P. Infantile optic atrophy with dominant mode of inheritance. A clinical and genetic study of 19 Danish families. Acta Ophthalmol Suppl 1959;37:1-146.

4 Hoyt CS. Autosomal dominant optic atrophy. A spectrum of disability. Ophthalmology 1980;87:245-51.

5 Kline LB, Glaser JS. Dominant optic atrophy. The clinical profile. Arch Ophthalmol 1979;97:1680-6.

6 Eliott D, Traboulsi EI, Maumenee IH. Visual prognosis in autosomal dominant optic atrophy (Kjer type). $A m \mathcal{F} O p h$ thalmol 1993;115:360-7.

7 Johnstone PB, Gaster RN, Smith VC, Tropathi R. A clinicopathologic study of autosomal dominant optic atrophy. $\mathrm{Am}$ $\mathcal{F}$ Ophthalmol 1979;88:868-75.
8 Kjer P, Jensen OA, Klinken L. Histopathology of eye, optic nerve and brain in a case of dominant optic atrophy. Acta Ophthalmol 1983;61:300-12.

9 Eiberg H, Kjer B, Kjer P, Rosenberg T. Dominant optic atrophy (OPA1) mapped to chromosome $3 \mathrm{q}$ region. 1 . Linkage analysis. Hum Mol Genet 1994;3:977-80.

10 Lunkes A, Hartung U, Magarino C, et al. Refinement of the OPA1 gene locus on chromosome 3q28-q29 to a region of 2-8 cM in one Cuban pedigree with autosomal dominant optic atrophy type Kjer. Am $\mathcal{F}$ Hum Genet 1995;57:968-70.

11 Bonneau D, Souied E, Gerber S, et al. No evidence of genetic heterogeneity in dominant optic atrophy. $\mathcal{F}$ Med genetic heterogeneity
Genet 1995;32:951-3.

12 Brown J, Fingert JH, Taylor CM, Lake M, Sheffield VC, Stone EM. Clinical and genetic analysis of a family affected with dominant optic atrophy (OPA1). Arch Ophthalmol 1997;115:95-9.

13 Johnston RL, Burdon MA, Spalton DJ, Bryant SP, Behnam JT, Seller MJ. Dominant optic atrophy, Kjer type. Linkage analysis and clinical features in a large British family. Arch Ophthalmol 1997;115:100-3.

14 Votruba M, Moore AT, Bhattacharya SS. Genetic refinement of dominant optic atrophy (OPA1) locus to within a $2 \mathrm{cM}$ interval of chromosome 3q. 7 Med Genet 1997;34: 117-21.

15 Jonasdottir A, Eiberg H, Kjer B, Kjer P, Rosenberg GT. Refinement of the dominant optic atrophy locus (OPA1) to a $1.4 \mathrm{cM}$ interval on chromosome 3q28-3q29, within a 3 Mb YAC contig. Hum Genet 1997;99:115-20.

16 Lathrop GM, Lalouel JM. Easy calculations of lod scores and genetic risks on small computers. Am f Hum Genet 1984;36:460-5.

17 Cottingham RW, Idury RM, Schaffer AA. Faster sequential genetic linkage computations. Am f Hum Genet 1993;53: 252-63.

18 Schaffer AA, Gupta SK, Shiram K, Cottingham RW. Avoiding recomputation in linkage analysis. Hum Hered 1994;44: 225-37.

19 Kruglyak L, Daly KJ, Reeve-Daly MP, Lander ES. Parametric and non-parametric linkage analysis: a unified multipoint approach. Am f Hum Genet 1996;58:1347-63.

20 Ott J. Analysis of human genetic linkage. Baltimore: Johns Hopkins University Press, 1985:112-5.

21 Lander ES, Green P. Construction of multilocus genetic linkage maps in humans. Proc Natl Acad Sci USA 1987;84: 2363-7.

22 Dib C, Faure S, Fizames C, et al. A comprehensive genetic map of the human genome based on 5264 microsatellites. Nature 1996;380:152-4. 